\title{
A review: Chemical and biological activity of chalcones with their metal complex
}

\author{
Thakor Shivani $\mathbf{R}^{1^{*}}$, Sharma Bhavesh $\mathbf{R}^{2}$ \\ ${ }^{1}$ Department of Chemistry, Uka Tarsadia University, Gujrat-394350, India \\ ${ }^{2}$ Department of Chemistry, Shri Jagdishprasad Jhabarmal Tibrewala University Vidhyanagari, Rajasthan-333001, India
}

\begin{abstract}
Chalcone is a fragrant ketone that frames a focal center for an assortment of significant organic mixes, which are altogether known as chalcones. They have various exercises like antibacterial, antifungal, mitigating and against tumor and so on relying upon the replacement made on them. Chalcones are regular item has a place with Flavonoid family. Chalcones are 1, 3-diphenyl-2-propene-1-one, in which two fragrant rings are connected by a three carbon $\alpha, \beta$-unsaturated carbonyl framework. Chalcones and their heterocyclic analogs appreciate a scope of organic exercises, for example, antimicrobial, cancer prevention agent, cytotoxic, anticancer, antiprotozoal, antihistaminic, antiulcer and calming exercises which makes these mixes as an extraordinary fascination for examination. Also the bielectrophilic, ketovinyl chain between the two rings is profoundly receptive and goes about as a significant synthetic synthon for building diverse five, six and seven part heterocyclic frameworks containing distinctive hetero molecules like nitrogen, oxygen and sulfur iotas by compressed version with an assortment of binucleophilic reagents.
\end{abstract}

Keywords: Chalcone, Metal complex, Synthesis, Aldol condensation, Claisen Schmidt condensation, Molecular spectral studies, Biological activity.

Accepted on June 19, 2020

\section{Introduction}

The term "Chalcones" was authored by Kostanecki and Tambor. Chalcones are 1, 3-diphenyl-2-propene-1-one, in which two fragrant rings are connected by a three carbon $\alpha, \beta$ unsaturated carbonyl framework. These mixes are otherwise called benzal acetophenone or benzylidene acetophenone. Chalcone are fragrant ketone that shapes the focal center for an assortment of significant organic mixes, which are referred to on the whole as chalcones. Chalcone are class of normal item. These are considered as antecedent of flavones in the biosynthesis of flavonoids and isoflavonoids and for the most part got from palatable plants. Chalcones are generally spread in nature (organic products, vegetables, flavors, tea and soybased food stuff) and their 2'-hydroxy subordinates assume a significant job in the flavonoid blend and biosynthesis as the two antecedents and items. They show different pharmacological activity, for example, antibacterial, antifungal, antitumor and calming properties. Chalcones are additionally intermediates in the Auwers blend of flavones. Chalcones can be set up by an aldol buildup between a benzaldehyde and an acetophenone within the sight of sodium hydroxide as an impetus. This response has been found to work in with no dissolvable by any stretch of the imagination -a strong state response. Artificially these are 1,3-diphenyl-2-propene-1-one, in which two sweet-smelling rings are connected by a three carbon $\alpha, \beta$-unsaturated carbonyl framework. It could be viewed as that their actual significance is stretched out in two branches (Figure 1). The natural action related with them, including calming, antimitotic, against leishmanial, hostile to obtrusive, hostile to tuberculosis, against contagious, against malarial, hostile to tumor, and against oxidant properties; just as their perceived engineered utility in the planning of pharmacologically-fascinating heterocyclic frameworks like pyrazolines, which have additionally been to a great extent considered inferable from their pharmacological exercises, which incorporates hostile to tumor mitigating, against parasitary, against burdensome, anticonvulsant, antimicrobial, antinociceptives and nitric oxide synthesis inhibitors, related with illnesses, for example, Alzheimer, Huntington, and provocative joint inflammation [1-5].

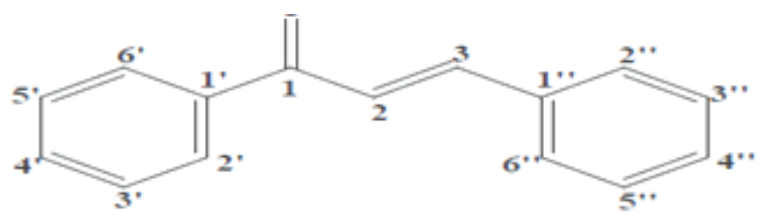

Figure 1. The general structure and numbering of chalcones.

All the chalcones give pink shading with concentrated sulphuric corrosive (positive Wilson test) and when a phenolic hydroxyl bunch is available, they give violet tinge with 
alcoholic ferric chloride arrangement. Chalcones on warming with hints of iodine in dimethylsulphoxide (DMSO) for two hours give the relating flavones. Chalcones were changed over into the comparing flavonols by their oxidation utilizing hydrogen peroxide in methanolic sodium hydroxide arrangement and these flavonols demonstrated a trademark greenish yellow fluorescence in ethanolic arrangement just as with concentrated sulphuric corrosive [6-8].

\section{Physical Properties of Chalcone}

The physical properties of chalcone are as per the following (Table 1):

Table 1. Physical properties of chalcone.

\begin{tabular}{ll}
\hline Molecular formula: & $\mathbf{C}_{15} \mathrm{H}_{12} \mathrm{O}$ \\
\hline Molar mass & $208.26 \mathrm{~g} \mathrm{~mol}^{-1}$ \\
\hline correct mass & 208.0888 \\
\hline Density & 1.071 \\
\hline Melting point & $55-57^{\circ} \mathrm{C}$ \\
\hline Boiling point & $345-348^{\circ} \mathrm{C}$ \\
\hline
\end{tabular}

\section{Engineered techniques for chalcones}

There are for the most part two modes for the blend of Chalcones:

By the buildup of acetophenones with benzaldehydes (Claisen-schmidt buildup)

By the buildup of phenols with cinnamoyl chloride by Friede 1-Specialties response.

Condensation of acetophenones with benzaldehydes (Claisen-schmidt buildup): Claisen-Schmidt buildup is most advantageous technique for the union of chalcones. The equimolar amounts of acetophenone and benzaldehydes are dense within the sight of watery alcoholic soluble base [19-26]. In the Claisen-Schmidt response, the grouping of soluble base utilized, for the most part runs somewhere in the range of 10 and $60 \%$. The response is done at about $50{ }^{\circ} \mathrm{C}$ for $12-15$ hours or at room temperature for multi week. Under these conditions, the Cannizzaro response likewise happens and subsequently diminishes the yield of the ideal item (Figure 2). To stay away from the disproportionation of aldehyde in the above response, the utilization of benzylidene-diacetate instead of aldehyde has been suggested [7-10].
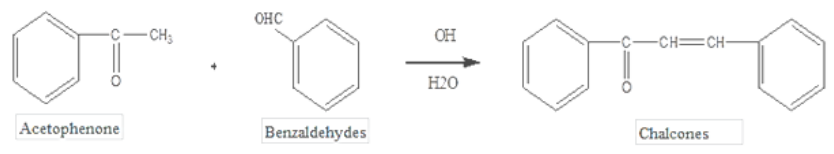

Figure 2. Condensation of acetophenones with benzaldehydes.

By the condensation of phenols with cinnamoyl chloride by Friedel-Crafts reaction: Other than the Claisen-Schmidt response, chalcones can likewise be orchestrated by direct
Friedel-Specialties acylation of a phenol. In this methodology the phenol turns into the A-ring while the acylating specialist gives both the B-ring carbons and the three-carbon extension to shape C6-C3-C6 unit. Friedel-Specialties acylation of 2, 4dimethyl-1, 3, 5-triolbenzene with 3-phenyl propionyl chloride gave 2, 4, 6'-trihydroxy-3, 5-dimethylchalcone. The Friedel Specialties responses are a lot of responses created by Charles Friedel and James Artworks in 1877 to connect substituents to a sweet-smelling ring. There are two primary sorts of Friedel Specialties responses: alkylation responses and acylation responses (Figure 3). Both continue by electrophilic fragrant replacement. The general response is demonstrated as follows [11-14].

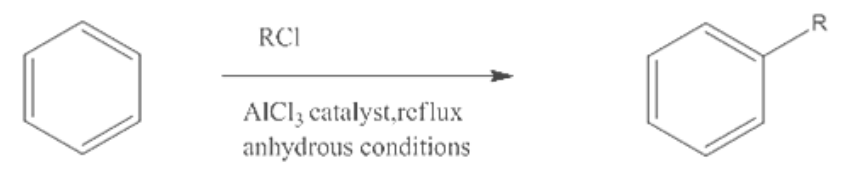

Figure 3. Condensation of phenols with cinnamoyl chloride by Friedel-Crafts reaction.

\section{Introduction of Chalcone Metal Complex}

Chalcones have been used as ligands in the formation of metal complexes. They can act as monodentate, bidentate or polydentate species towards the metal complexes depend on the number of donor atoms present the compound. If there is one or more donor atoms present near to the carbonyl group, the chalcones can form chelate metal complexes. Chalcone derivatives can form complexes with different metal ions due to their good synthetic flexibility, selectivity and sensitivity towards the central metal atom (Figure 4). They are able to form complexes with $\mathrm{Mn}(\mathrm{II}), \mathrm{Co}(\mathrm{II}), \mathrm{Ni}(\mathrm{II}), \mathrm{Cu}(\mathrm{II}), \mathrm{Zn}(\mathrm{II})$, $\mathrm{Cd}(\mathrm{II}), \mathrm{Ru}(\mathrm{III})$ and $\mathrm{Rh}(\mathrm{III})$ [15].

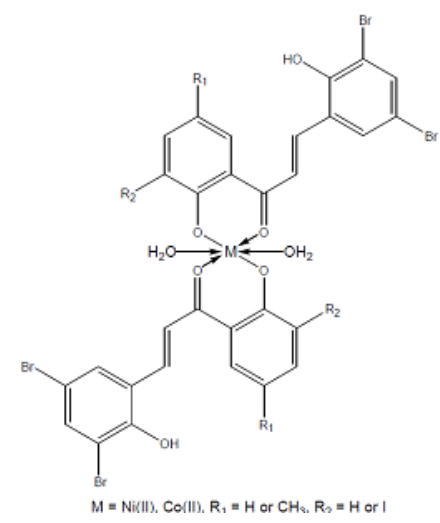

Figure 4. Structure of chalcone metal complex.

The metal complexes of chalcones can be tetrahedral, square planar or octahedral geometry depend on the coordination number in the complex, the nature of the metal atom, and the magnitude of the ligand field. Palaniandavar and Natarajan (1980) studied the Co(II), Ni(II), and Cu(II) complexes of 2' hydroxy-5' $-\mathrm{X}$-chalcone where $\mathrm{X}=\mathrm{H}, \mathrm{CH}_{3}, \mathrm{Cl}$. They reported that metal(II) complexes of 2' -hydroxychalcone have lowspin square planar configuration. The extensive conjugation of carbonyl group with the phenyl ring led to greater electrons 
delocalisation. The most widely studied chalcone ligands is ohydroxychalcones such as 3-(phenyl)-1-(2 , hydroxynaphthyl)-2-propen-1-one, 3-(3, 4-dimethoxypheny)-1(2, -hydroxyphenyl)-2-propen-1-one, 3-(4-chlorophenyl)-1(2' -hydroxynaphthyl)-2-propen-1-one and so on. These ligands have the capability to form chelates with metal ions through the oxygen atoms of carbonyl and phenolic group [16-18].

This delocalisation brought down the vitality level of the counter $\pi$ orbital. Therefore, the $\mathrm{M} \rightarrow \mathrm{L}$ back holding happened and prompted an expansion in the ligand field quality. Subsequently, the ligand field delivered is sufficiently able to balance out the square planar coordination and the turn blending happen. Rao and his associates (1988) had examined the planning conduct of 3-(2-pyridyl)-1-(2-hydroxy phenyl)-2propen-1-one (PHPO), 3-(1-naphthyl)-1-(2-hydroxy phenyl)-2propen-1-one (NHPO) and 3-(3, 4-dimethoxy phenyl)-1-(2hydroxy phenyl)-2-propen-1-one (DMPHPO) with Co(II), $\mathrm{Ni}(\mathrm{II}), \mathrm{Cu}(\mathrm{II}), \mathrm{Zn}(\mathrm{II})$ and $\mathrm{Cd}(\mathrm{II})$. The ligand PHPO was found to go about as uninegative tridentate towards $\mathrm{Co}$ (II) and $\mathrm{Ni}$ (II) and bidentate towards $\mathrm{Cu}(\mathrm{II}), \mathrm{Zn}$ (II) and $\mathrm{Cd}(\mathrm{II})$. While, the NHPO and DMPHPO ligands go about as uninegative bidentate towards every metal particle. In light of their electronic otherworldly information, the PHPO complex of $\mathrm{Co}(\mathrm{II})$ and $\mathrm{Ni}$ (II) are octahedral and NHPO and DMPHPO complex of $\mathrm{Cu}$ (II) and $\mathrm{Ni}$ (II) are square planar. The complex of $\mathrm{Zn}(\mathrm{II})$ and $\mathrm{Cd}(\mathrm{II})$ demonstrated tetrahedral geometry.

Habib and his associates (2011) examined a progression of subbed 2'-hydroxychalconesCo(II), Ni(II) and $\mathrm{Cu}$ (II) buildings. The stoichiometry of the buildings was 1:2 metals to ligand proportion and the subbed 2'-hydroxychalcone ligands went about as mononegativebidentate towards the metal edifices (Figure 5). In light of their discoveries, $\mathrm{Co}(\mathrm{II})$ and $\mathrm{Ni}(\mathrm{II})$ edifices were found to have octahedral geometry because of quality of two composed water particles in the buildings [19-22].

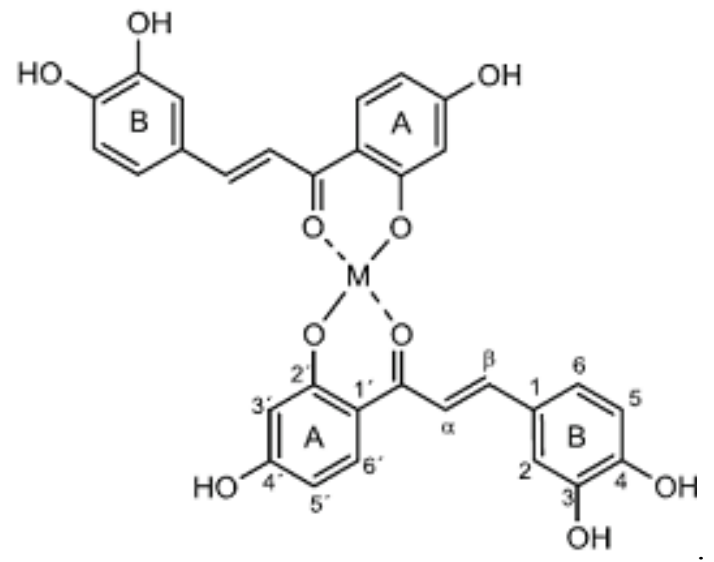

Figure 5. Structure of general M(II) chalcone complex.

\section{The color in transition metal complex}

Color is distinctive group property of coordination compounds of transition metals.

Table 2. Color in Transition metal complex.

\begin{tabular}{llll}
\hline Changing Ligands & & & \\
\hline Ligands & Color & Shape & $\begin{array}{l}\text { Absorbance } \\
\text { Value }\end{array}$ \\
\hline$\left[\mathrm{Cu}\left(\mathrm{H}_{2} \mathrm{O}\right)_{6}\right]^{2+}$ & Blue & Octahedral & $880 \mathrm{~nm}$ \\
\hline$\left[\mathrm{Cu}\left(\mathrm{NH}_{3}\right)_{4}\left(\mathrm{H}_{2} \mathrm{O}\right)_{2}\right]^{2+}$ & $\begin{array}{l}\text { Blue- } \\
\text { Voilet }\end{array}$ & Octahedral & $660 \mathrm{~nm}$ \\
\hline Changing Co-ordination Number & & \\
\hline Ligands & Color & Shape & $\begin{array}{l}\text { Absorbance } \\
\text { Value }\end{array}$ \\
\hline$\left[\mathrm{Cu}\left(\mathrm{H}_{2} \mathrm{O}\right)_{6}\right]^{2+}$ & Blue & Octahedral & $880 \mathrm{~nm}$ \\
\hline$[\mathrm{CuCl}]^{2-}$ & Yellow & Tetrahedral & $\begin{array}{l}880 \mathrm{~nm} \text { and } 380 \\
\mathrm{~nm}\end{array}$ \\
\hline
\end{tabular}

The octahedral complex of cobalt exist in a wide spectrum of colors, which depend on the groups coordinated to it. Such coordination groups are called ligands. In solution color arises from the association of solvent molecules with the metal as ligands and not form the metal cation itself. In concentrated sulfuric acid $\mathrm{Cu}^{+2}$ is colorless, in water it is aquamarine and in liquid ammonia it is a deep ultamine.

Whenever a certain energy of visible electromegnatic radiation $\mathrm{E}$ is absorbed by a compound during the excitation of an electron to a higher quantum state the wavelength of light absorbed can be calculated from the expression.

$\mathrm{E}=\mathrm{hv}=\mathrm{hcv}$

Where $\mathrm{h}$ is plancks constant, $\mathrm{v}$ is frequency, and $\mathrm{c}$ is speed of light. If the energy is given in wave numbers, as frequently is done then the wave length is simply the reciprocal the colour that we see in the compound is complemetry color $[23,24]$.

\section{Properties of change metal complex}

Highly shaded (assimilate light in noticeable, transmit light which eye distinguishes)

Metals may display various oxidation states

Metals may display paramagnetic subject to metal oxidation state and on ligand field.

\section{Anticancer Copper Complex}

Anticancer action of copper (I) mixes might be an aftereffect of various components, that is their capacity to deliver receptive oxygen species (ROS). Copper (I) particles can lessen hydrogen peroxide to hydroxyl radical. Copper (II) particles may thusly be diminished to $\mathrm{Cu}$ (I) by superoxide anion (O2•-), or glutathione. In this way, it tends to be reasoned that the creation of receptive oxygen species, for example, $\mathrm{OH} \bullet$ are 
driven by the copper, paying little mind to the structure in which it is at first brought into the body $-\mathrm{Cu}^{+}$, or $\mathrm{Cu}^{2+}$ :

$\mathrm{Cu}_{2}++\mathrm{O} 2 \cdot-\rightarrow \mathrm{Cu}++\mathrm{O}_{2}$

$\mathrm{Cu}+\mathrm{H}_{2} \mathrm{O}_{2} \rightarrow \mathrm{Cu}_{2}++\mathrm{OH} \bullet+$ Goodness

Superoxide anion (O2•-) is the result of decrease of the subatomic oxygen that happens in numerous organic procedures. It is changed over into hydrogen peroxide through dismutation. Both of these types of ROS lead to the arrangement of another kind of responsive oxygen species - the hydroxyl radical $(\mathrm{OH} \bullet)$. It happens in a response catalyzed by copper (or iron) particles. This radical is accepted to be the primary factor causing DNA harm in cells under oxidative pressure.

Pyridine subordinates assume critical job in numerous organic frameworks as the part of a few nutrients, nucleic acids, compounds and proteins. Be that as it may, concentrates on the antimicrobial exercises of their metal buildings are uncommon in writing. Metal edifices containing nitrogen and sulfur givers have been end up being potential antibacterial and fungial operators just as part of a few nutrients and medications. The official of metal particles to nicotinanilide bunches has been a subject of expanding interest, in light of the fact that a large number of these responses give basic models to substantially more perplexing metal peptide frameworks and chemicals. We report here the blend, portrayal and natural exercises of some new nickel (II), copper (II) and zinc (II) blended ligand buildings containing nicotinanilide and thiocyanate as ligands. The integrated buildings are described by basic, IR and electronic spectroscopic examination (Figure 6).

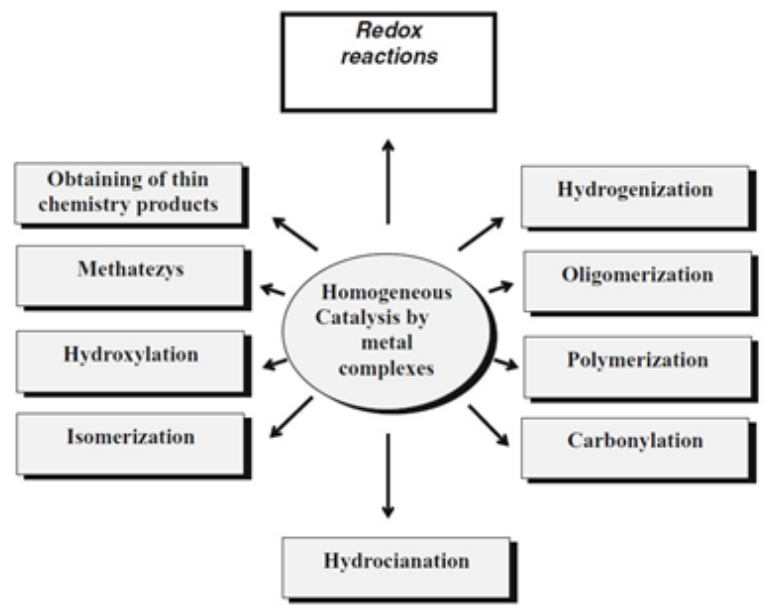

Figure 6. Application of homogeneous catalysis with the transition metal complex.

Some transition metal complex are diamagnetic, which indicates no unpaired electrons. Many others are paramagnetic and have one or more unpaired electrons. For example, $\left(\mathrm{CONH}_{3}\right)_{6}$ Is a diamagnetic, where as cof6 is paramagnetic and has four unpaired electrons per ion. The ionic charge is not the governing factor since $\mathrm{fe}\left(\mathrm{H}_{2} \mathrm{O}\right)$ which has four unpaired electrons is paramagnetic yet $\mathrm{Fe}(\mathrm{CN})_{6}$ is diamagnetic.

\section{Molecular Spectral Studies of Chalcones Ultra Violet Spectroscopy}

The significant retention band in chalcones (Band I) as a rule happens in the range $340-390 \mathrm{~nm}$, in spite of the fact that chalcones lacking B-ring oxygenation may have their Band I assimilation at impressively shorter frequencies and Band II is typically a minor top in the $220-270 \mathrm{~nm}$ region. In the spectra of chalcones containing a free 4"-hydroxyl gathering, the expansion of $\mathrm{NaOMe}$ causes a 60-100 nm bathochromic move of Band I with an increment in top force. Chalcones without a 4"-hydroxyl gathering yet with either a free 2" or 4'-hydroxyl bunch additionally give, within the sight of NaOMe, a 60-100 $\mathrm{nm}$ bathochromic move of Band I however without an expansion in top intensity. UV spectroscopy demonstrated helpful to recognize subbed chalcones and flavanones, which is beyond the realm of imagination by EI mass spectrometry because of warm isomerization of 2'-hydroxychalcones in the particle source.

\section{Infra red spectroscopy}

The $\alpha, \beta$-unsaturated carbonyl gathering, normal for a chalcone typically show up as a noticeable band in the middle of $1625-1650 \mathrm{~cm}^{-1}$ in its IR range. The area at which other assimilation groups show up relies upon the kind of sweetsmelling/heteroaromatic rings just as the substituents present on these rings.

\section{NMR spectroscopy}

The $\mathrm{H}-\alpha$ and $\mathrm{H}-\beta$ protons of chalcones happen as two doublets $(\mathrm{J}=17 \mathrm{~Hz})$ in the extents $6.7-7.4 \mathrm{ppm}(\mathrm{H}-\alpha)$ and $7.3-7.7$ ppm $(\mathrm{H}-\beta)$ in the $1 \mathrm{H}$ NMR spectra. The other fragrant protons normally show up in the middle of $\delta 6.9-8.0$, contingent upon the sort of sweet-smelling/heteroaromatic ring and furthermore dependent on the electronic impacts of the substituents present on these rings. The huge $\mathrm{J}$ esteem $(17 \mathrm{~Hz})$ unmistakably uncovers the trans geometry for the chalcones. The carbonyl carbon of the chalcones normally shows up between $\delta 188$. 6 and 194. 6 in its 13C NMR spectrum. The $\alpha$ and $\beta$-carbon particles regarding the carbonyl gathering offer ascent to trademark flags in the middle of $\delta 116.1-128.1$ and $\delta 136$. 9-145. 4 separately, which can likewise be promptly distinguished by their trademark appearance as a six line multiplet in the half reverberation decoupled spectrum. The nearness of 2'-hydroxy gathering shifts the carbonyl carbon move downfield by 3 ppm comparative with relating acetoxy and methoxy mixes, probably attributable to hydrogen holding. The $\beta$-hydroxychalcones are a generally little gathering of chalcones that happen normally once in a while as the enoltautomers of dibenzoylmethane subsidiaries. The degree of keto-enoltautomerism is generally dissolvable ward, and atomic attractive reverberation spectroscopy (NMR) gives perhaps the best technique to decide the proportion of the tautomers present. In the $1 \mathrm{H}$ NMR spectra recorded in $\mathrm{CDCl} 3$, the replaceable proton of the $\beta$-Gracious of the enol tautomer shows up as a $1 \mathrm{H}$ singlet at $\delta 16.0$, while the $\alpha-\mathrm{CH} 2$ protons of the keto tautomer show up as a $2 \mathrm{H}$ singlet at $\delta$ 4. 50. Another 
analytic reverberation is the $1 \mathrm{H}$ methine singlet of the enol tautomer $(\alpha-\mathrm{CH})$, which is found at $\delta 6.5$, with its relating $\mathrm{C}-\alpha$ reverberation at $\delta 90$ to 92 in the 13C NMR spectra [26].

\section{Mass spectrometry}

Cleavage of the heterocyclic C-ring by means of a retro DielsBirch (RDA) component speaks to a significant fracture pathway in chalcones. RDA parting prompts two trademark pieces, which gives helpful data concerning the quantity of hydroxyl, methoxyl and different substituents on each ring. A similar data was likewise acquired by a HPLC-tandam mass spectrometer framework outfitted with a warmed nebulizer-air pressure concoction ionization (APCI) interface [10].

\section{Organic Exercises of Chalcones}

Various normally happening chalcones just as their subordinates have been secluded from different sources and related to various organic exercises. The nearness of $\alpha, \beta$ unsaturated carbonyl framework chalcones makes it natural actuate. Some subbed of chalcones and their subsidiaries including a portion of their heterocyclic analogs have been accounted for to have some intriguing natural properties. The nearness of $\alpha, \beta$ unsaturated carbonyl in chalcones shows antibacterial exercises against $\mathrm{S}$. aureus, E. Coli, C. albicans, T utillis, and some different living beings. Some nitrofurylschalcones have been orchestrated and tried for their bacterial movement. Among the every one of those derivates, the most proficient is which repressed staphylococcus London at $1 \mathrm{ug} / \mathrm{ml}$. Severalchalcones having general structure have been blended and tried for their antibacterial and antifungal exercises [24].

\section{Anticancer action}

Among the as of now distinguished antitumor operators, chalcones speak to a significant class of particles. Deregulation of apoptosis or modified cell passing, in multicellular creatures is a significant supporter of the endurance of tumor cells. The procedure of apoptosis can be partitioned into two sections, sensors and effectors. The sensors (extraneous pathway) are liable for checking the extracellular and intracellular condition for conditions that impact whether a cell should live incredible. These signs direct the inferior of segments (natural pathway or mitochondrial apoptosis pathway), which capacity to prompt apoptotic demise. Chalcones have been found to act through the inherent just as extraneous apoptosis pathway to forestall tumor movement. Customs from various geological locales of the world and distinctive timeframes have archived the broad utilization of liquorice for the fix of various human infirmities including as an enemy of ulcer operator. Current investigations have recognized distinctive chalcones and flavonoids as the dynamic elements for their action. Chalcones like isoliquiretigenin, licochalconeAn, and licochalcone have been disengaged from liquorice and answered to be powerful against a progression of human malignancy cell lines (Figures 7 and $8)$.<smiles>COc1ccc(/C=C/C(=O)c2c(O)cc(OC)cc2OC)cc1</smiles>

Figure 7. Structure of Flavokawain A.<smiles>O=C(/C=C/c1ccc(O)cc1)c1ccc(O)cc1O</smiles>

Figure 8. Structure Of Isoliqiretigenine.

Xiaolin et al. isolated Flavokawain A from Kava extract, which was found to be a suppressor of bladder tumour growth. In addition to these natural chalcones, a number of chalcones have been synthesised and reported to show anticancer activities.

\section{Antioxidant activity}

Cell reinforcements are the intensifiers that forestall the oxidative harm, instigated by free radicals and receptive oxygen species, which is answerable for some pharmacological occasions such malignancy and maturing and so on. Chalcones, by and large, fill in as dynamic member in plant safeguard systems to neutralize the receptive oxygen species to diminish the pulverization at atomic level and the harm brought about by microorganisms, bugs and herbivores. The cancer prevention agent movement of these mixes is connected with different components like metal particle chelation, free extreme utilization, move of an electron or hydrogen iota, singlet oxygen extinguishing and going about as substrate for radicals like hydroxide and superoxides

Free radicals are being framed during typical cell digestion and they are known to add to sound capacities in human wellbeing and improvement when they are not over the top. An instrument for adjusting the development of free radicals and their detoxification is fundamental for typical cell work. At the point when such a parity is disturbed because of unnecessary age of harming species or low degrees of cancer prevention agents, a cell goes into a condition of oxidative pressure and is harmed. On the off chance that the harm perseveres, the cell will enter a condition of hereditary insecurity that can prompt interminable infections including malignant growth.

Numerous chalcones have been separated from characteristic sources with great cancer prevention agent properties. Karanjapin was separated from the root bark of Pongamia pinnata and found to have critical cancer prevention agent activity. Paratocarpin B, segregated from Glycyrrhiza glabra was related to cell reinforcement movement (Figures 9 and 10). 
<smiles>COC(=O)C(O)=C(O)c1ccc2c(c1)OCO2</smiles>

Figure 9. Structure of Karanjapin.<smiles>CC(C)=CCc1cc(/C=C/C(=O)c2ccc3c(c2O)C=CC(C)(C)O3)ccc1O</smiles>

Figure 10. Structure of Paratocarpin B.

\section{Antimicrobial activity}

The expanding occurrence of disease brought about by the fast improvement of bacterial protection from a large portion of the realized anti-microbials is a genuine medical issue. The expanding number of multi sedate safe organisms animates look into endeavors for finding powerful nature determined therapeutics.

Salem et al. detailed the separation and leishmanicidal movement of chalcones from methanolic concentrate of Psorothamnus polydenius. Prenylated dihydrochalcones were separated from Boronia bipinnata with antimalarial Movement (Figure 11 and 12).
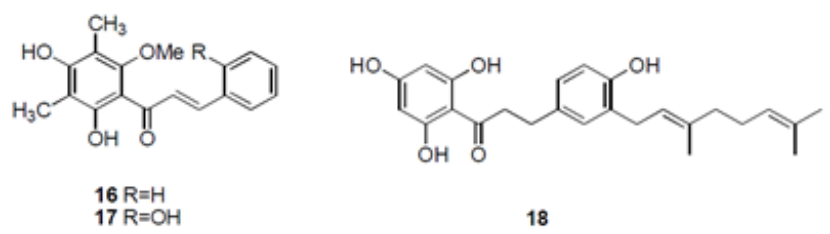

18

Figure 11. Leishmanicidal activity of prepared chalcones.<smiles>CC(C)=CCC/C(C)=C/CC/C(C)=C/Cc1cc(CCC(=O)c2c(O)cc(O)cc2O)ccc1O</smiles>

19

Figure 12. Antimalarial activity of prepared chalcone.

\section{Antidepressant activity}

Medications accessible for relieving sadness, an intense conduct issue related with mind which may even initiate selfdestructive qualities, are related with a few bothersome symptoms. So there is a pressing unavoidable requirement for increasingly productive antidepressants with least unbearable reactions. Propelled from the way that a hydroxyl chalcone got by focal ring opening of normally existing flavonoid, Apigenin (bearing upper action) was found to have stimulant movement, Xin Sui et al. integrated a progression of 2', 4', 6'trihydroxychalcones and assessed them for their stimulant action in male Kunming mice (20-24 g, nearby variety) by utilizing constrained swimming test (FST) and tail suspension test (TST). Fluoxetine was taken as reference for contrasting the outcomes. One of the tried compound, 3-(2bromophenyl)-1-(2', 4', 6'-trihydroxyphenyl)prop-2-en-1-one $(10 \mathrm{mg} / \mathrm{Kg}$ ) was seen as most dynamic energizer with a noteworthy diminishing in length of idleness (time of fixed status $=69.4 \mathrm{~s}$ and for reference it was $57.4 \mathrm{~s}$ at same portion level). Results uncovered the impact of nature of different substituents and their situation in ring B onantidepressant action of various chalcones (Figure 13).

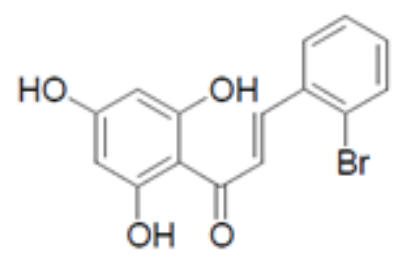

Figure 13. 3-(2-bromophenyl)-1-(2', 4', 6'-trihydroxyphenyl)prop-2en-1-one.

\section{Antifungal activity}

One chalcone conveying 2, 5-dichlorothiophene moiety and unsubstituted phenyl ring was seen as most strong antifungal specialist with zone of hindrance of $26 \mathrm{~mm}$ for each strain separately. It was much more dynamic than the standard one. Other two mixes with piperazine moiety were exceptionally dynamic operators having zone of hindrance and MIC values similar with that of the most dynamic chalcone in this investigation. From this investigation, it was likewise discovered that mixes subbed with electron negative nitro bunch were less dynamic towards the restraint of contagious development (Figure 14).
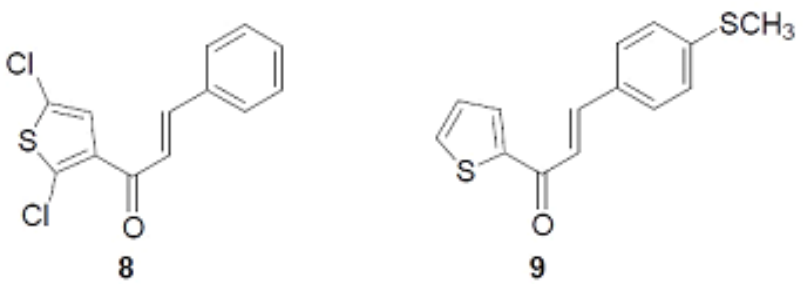

Figure 14. Chalcone carrying 2, 5-dichlorothiophene moiety and unsubstituted phenyl ring.

\section{Conclusion}

Chalcones are dumbfounding stages for produced controls just as have different normal and restorative properties. This review article is corresponding to the past overviews and has been revolved around the latest pharmacological activities appeared by different chalcone. Analogs dependent on heterocyclic moiety. The introduction of a heterocyclic structure unsaturated system indicated a broad scope of pharmacological activities. The helpful potential about heteroarylchalcones gave in the back and forth movement review can be important for the future assessment of this stage in order to survey their natural potential in a prevalent way and for the disclosure of further 
lead moiety for the treatment of various ailments. The various activities of chalcone consolidates antimicrobial, quieting, torment easing, antiplatelet, antiulcerative, antimalarial, anticancer, antiviral, antileishmanial, disease avoidance specialist, antitubercular, antihyperglycemic, immunomodulatory, block of mixture center individuals release, obstruction of leukotriene B4, restriction of tyrosinase what's more, deterrent of aldose reductase works out.

\section{References}

1. Prasad YR, Kumar PR, Deepti CA, et al. Synthesis and Antimicrobial Activity of Some Novel Chalcones of 2Hydroxy -1-Acetonapthone and 3-Acetyl Coumarin. JChem. 2006; 3: 236-241.

2. SK Kumar, Hager E, Pettit C, et al. Design, Synthesis, and Evaluation of Novel Boronic-Chalcone Derivatives as Antitumor Agents. J Med Chem. 2003; 46: 2813-2815.

3. Tatsuzaki J, Bastow KF, Nakagawa-Goto K, et al. Dehydrozingerone, chalcone, and isoeugenol analogues as in vitro anticancer agents. J Nat Prod. 2006; 69:1445-1449.

4. Yun JM, MH Kweon, Kwon H, et al. Induction of apoptosis and cell cycle arrest by a chalconepanduratin a isolated from kaempferiapandurata in androgen-independent human prostate cancer cells PC3 and DU145. Carcinogenesis. 2006; 27: 1454-1464.

5. Kim BT, KO Joong, Chun CJ, et al. Synthesis of dihydroxylatedchalcone derivatives with diverse substitution patterns and their radical scavenging ability toward DPPH free radicals. Bull Korean Chem Soc. 2008; 29: 1125-1130.

6. Yoon G, Kang BY, Cheon SH. Topoisomerase i inhibition and cytotoxicity of licochalcones A and E fromGlycyrrhiza inflate. Arch Pharm Res. 2007; 30: 313-316.

7. Durst HD, Gokel GW. Experimental Organic Chemistry. 2nd edn, McGraw-Hill Publishing Company, New York, 1987, 428-430.

8. S Sebti, A Solhi, R Tahir, et al. Calcined sodium nitrate/ natural phosphate: An extremely active catalyst for the easy synthesis of chalcones in heterogenous media. Tetrahedron Lett. 2001; 42: 7953-7955.

9. Lopez J, Jacquot R, Figueras F. Heterogeneous catalysis of aldolisations on activated hydrotalcites. Stud Surf Sci Catal. 2000; 130: 491-496.

10. Watanabe K, Imazawa A. Aldol condensations catalyzed by Co (II) complexes of pyridine-containing copolymers. Bull ChemSoc Jpn. 1982; 55: 3208-3211.

11. Cheng MS, Li RS, Kenyon G. A solid phase synthesis of chalcones by Claisen-Schmidt condensations. Chin ChemLett. 2000; 11: 851-854.

12. Salehi P, Khodaei MM, Zolfigol MA. A Keyvan, Solventfree crossed aldol condensation of ketones with aromatic aldehydes mediated by magnesium hydrogensulfate.Monatsheftefuer Chemie. 2002; 133: 1291-1295.
13. F Fringuelli, F Pizzo, C Vittoriani, et al. Polystyrylsupported TBD as an efficient. Chem Commun. 2004; 130: 2756-2757.

14. Sondhi SM, Singhal N, Johar M, et al. Heterocyclic compounds as inflammationinhibitors. Curr Med Chem. 2002; 9: 1045-1074.

15. Mohareb RM, Zaki MY, Abbas NS. Synthesis, AntiInflammatory and Anti-Ulcer Evaluations of Thiazole, Thiophene, Pyridine and Pyran Derivatives Derived From Androstenedione. Steroids. 2015; 98: 80-91.

16. Booth NH, Mcdonald LE Drug and Chemical reduces in the eduble tissues of animal. In Veterinary Pharmacology and Therapeutics. 6th edn. 1988; 1149-1205.

17. Ciofalo VB, Latranyi MB, Patel JB, et al. Flunixin meglumine: A non-narcotic analgesic. J PharmacolExpTher. 1977; 200: 501-507.

18. Brun P, Dean A, Di MV, et al. Peroxisome proliferatoractivated receptor-gamma mediates the anti-inflammatory effect of 3-hydroxy-4-pyridinecarboxylic acid derivatives: synthesis and biological evaluation. Eur J Med Chem. 2013; 62: 486-497.

19. Gudasi KB, Vadavi RS, Shenoy RV, et al. Five-coordinate cobalt (II), nickel (II) and zinc (II) complexes derived from 2-pyridine-2-yl-3-(pyridine-2-carboxylideneamino)-1, 2dihydroquinazolin-4 (3H)-one. Transit Met Chem. 2005; 30: 661-668.

20. Gudasi KB, Vadavi RS, Shenoy RV, et al. Crystal Structure of 2-thiophene-2-yl-3 (thiophene-2-carboxylideneamino)-1, 2-dihydroquinazolin-4(3H)-one and the Synthesis, Spectral and Thermal Studies of its Transition Metal (II) Complexes. Transit Met Chem. 2006; 31: 374-381.

21. Gudasi KB, Patil SA, Vadavi RS, et al. Crystal structure of 2-[2-hydroxy-3-methoxyphenyl]-3-[2-hydroxy-3-

methoxybenzylamino]-1, 2-dihydroquinazolin-4(3H)-one and the synthesis, spectral and thermal investigation of its transition metal complexes. Transit Met Chem. 2006; 31: 586-592.

22. Gudasi KB, Shcnoy RV, Vadavi RS, et al. New lanthanide (llf) complexes of biologically active 2, 3-disubstituted quinazoline-4-(3H)-one: Synthesis, characterization and biological studies. Indian J Chem. 2005; 44A: 2247-2254.

23. Gudasi KB, Havanur VC, Patil SA, et al. Antimicrobial Study of Newly Synthesized Lanthanide(III) Complexes of 2-[2-hydroxy-3-methoxyphenyl]-3-[2-hydroxy-3methoxybenzylamino]-1, 2-dihydroquinazolin-4(3H)-one. Met Based Drugs. 2007: 37348.

24. Hoonur RS, Patil BR, Badiger DS, et al. Transition metal complexes of 3-aryl-2-substituted 1, 2-dihydroquinazolin-4 $(3 \mathrm{H})$-one derivatives: New class of analgesic and antiinflammatory agents. Eur J Med Chem. 2010; 45: 2277-2282.

25. Masarwa AS, Herron N, Fendrick CM, et al. Synthesis, Characterization, Anti-Microbial and Anti-Inflammatory activity, Studies of Novel Schiff base 3, 3' $-\{1,2-$ PhenyleneBis[Nitrilo(E) Methylydine]\} Diquinolin-2-ol and its Metal(II) Complexes. Inorg Chem. 1994; 42: 1086. 
26. Anjaneyalu Y, Rao RP. Preparation, Characterization and Antimicrobial Activity Studies on Some Ternary Complexes of $\mathrm{Cu}$ (II) with Acetylacetone and Various Salicylic Acids. . Synth. React Inorg Org Chem. 1986; 16: 257-272.

\section{*Correspondence to}

Thakor Shivani R

Department of Chemistry

Uka Tarsadia University

Gujrat, India

E-mail: bhavesh.unity143@gmail.com 